\title{
Consumer-assisted Selection of Blueberry Fruit Quality Traits
}

Jessica L. Gilbert and James W. Olmstead ${ }^{1}$

Horticultural Sciences Department, University of Florida, Gainesville, FL 32611

\section{Thomas A. Colquhoun, Laura A. Levin, and David G. Clark \\ Department of Environmental Horticulture, University of Florida, Gainesville, FL 32611}

\author{
Howard R. Moskowitz \\ Moskowitz Jacobs Inc., White Plains, NY
}

Additional index words. blueberry breeding, flavor, fruit quality, Vaccinium corymbosum

\begin{abstract}
Blueberries are a high-value fruit that has experienced extraordinary growth in consumption in the past decade. Maintaining this growing market requires an understanding of the current market and its potential for expansion. To assay the impact of 36 specific blueberry sensory and psychological traits on consumer interest, a blueberry fruit quality study was constructed using techniques that allow many features to be tested in an analysis by combining specifics from different categories that describe a product. Individual traits that most impact the likelihood of fruit purchase were identified. Sweet and intense blueberry flavor yielded the most positive purchase interest, whereas bad texture attributes such as seediness were the most detrimental to interest. It was also possible to define two interest segments within the survey population that shared similar responses to particular experimentally assayed traits. The larger segment of the sample population $(61 \%)$ was most interested in the aspects of blueberry flavor, whereas the second segment of respondents $(39 \%)$ was most influenced by health aspects commonly associated with blueberry fruit consumption. Both segments responded negatively to bad texture. This study suggests that breeders and producers should exploit genetic and environmental variables that contribute to improved blueberry flavor and that marketing strategies to sell blueberry cultivars of superior flavor may be appropriate.
\end{abstract}

Blueberries [northern highbush (Vaccinium corymbosum), southern highbush (V. corymbosum hybrids), rabbiteye ( $V$. virgatum), and lowbush ( $V$. angustifolium) ] are an economically important small fruit crop in the United States with 277 million pounds harvested for fresh production valued at $\$ 850.8$ million U.S. in 2012 (USDA, 2013). Blueberry acreage continues to increase worldwide in accordance with growing demand for these antioxidant-rich fruit. Although native to North America, breeding programs have developed blueberry cultivars that grow in a wider array of climates, allowing production to flourish in South America, Europe, Asia, and Australia. Global highbush blueberry production passed the one billion pound mark in 2012 and continues to accelerate (Brazelton, 2013). Historically, many traits have been selected for in blueberry breeding programs with producers in mind, including climatic adaptation, yield, mechanical harvest potential, and disease resistance. Conversely, the fruit quality traits of interest to the consumer

Received for publication 14 Feb. 2014. Accepted for publication 28 May 2014.

The University of Florida Plant Innovation Program thanks the University of Florida Plant Molecular Breeding Initiative for funding.

${ }^{1}$ To whom reprint requests should be addressed; e-mail jwolmstead@ufl.edu. are what should ultimately fuel production and profitability. In recent surveys, only $48 \%$ of U.S. consumers had bought blueberries in the past 12 months compared with $88 \%$ of consumers who had bought the highest selling fruit, bananas (Fresh Trends, 2013). Of the $48 \%$ of U.S. consumers who purchased blueberries in the past year, $15 \%$ of these consumers were reportedly regular buyers of blueberries (Brazelton, 2013; Fresh Trends, 2013). Converting seldom purchasers into frequent purchasers through product satisfaction could have a beneficial impact on the blueberry market. To provide this level of product satisfaction, it is critical to assess the expectations and desires of the current blueberry consumer to make sure these parameters are being met. Increasing market penetration for the $50 \%$ of consumers who did not purchase blueberries in the past 3 years will be important to drive continued expansion of blueberry production as well (Brazelton, 2013; Fresh Trends, 2013).

Developing a new blueberry cultivar with improved traits for the producer or consumer is a long-term process. From the time an initial cross between two blueberry parents is made, the earliest a resulting progeny is typically considered for release is 10 years. This plant must then be marketed to nurseries or farmers who mass propagate the clones, which means that the blueberry breeder designing the parental crosses is catering to an industry nearly two decades in the future. Breeders often work closely with the producers and are therefore aware of the changing needs of farmers. However, consumer satisfaction with the end product is influencing new directions in research and development of horticultural crops, encouraging breeder focus on traits such as improved strawberry (Fragaria $\times$ ananassa) flavor (Colquhoun et al., 2012) and flower fragrance (Levin et al., 2012). With lengthy breeding cycles, it is critical to empirically assay the psychological influences of consumer blueberry purchases before committing to years of manipulating traits that may not actually affect marketability. Additionally, this information could be used to tailor messages directed to the consumer through commercial marketing, in advertisements, and on packaging.

When a consumer encounters a product, multiple attributes of the product may influence their purchase decision. The consumer may not necessarily be rational or consciously aware of the reasoning for this decision, and outright asking of the consumer to identify their desires may introduce cognitive bias (DellaVigna, 2009; Price and Riis, 2012; Redelmeier and Dickinson, 2011). Additionally, attempting to test a high number of variables for psychological impact can cause subject frustration and cognitive burden (Park and Lessig, 1981). Both of these issues can be tackled using modified conjoint analysis and rule-developing experimentation. In this approach, the consumer is presented with sets of three to four individual descriptive phrases or elements at a time, which reduces the variable load on the respondent. By posing many scenarios in which a product has a few attributes in different combinations, it is then possible to pull out individually impactful elements from the scheme (Behe, 2006; Behe et al., 1999, 2013; Jaeger et al., 2011; Moskowitz, 2012; Moskowitz et al., 2006; Moskowitz and Gofman, 2007). This method has been previously implemented to analyze favorable characteristics of fresh strawberries and flowers as a tool to guide breeding efforts in these horticultural crops (Colquhoun et al., 2012; Levin et al., 2012). The strawberry study identified sweetness and complex flavors as the most important traits to consumers, resulting in a large amount of effort and resources that have been devoted to biochemically characterizing strawberry flavor for identification of enhanced quality cultivars (Schwieterman et al., 2014).

This study was conducted as part of an ongoing effort to implement consumerassisted selection in horticultural breeding programs. Consumer-assisted selection is an approach to product development that seeks to identify which features are of most importance to the end user, an ambition that can be sometimes be diluted along a complex supply chain. We sought to identify which blueberry traits are of most importance to consumers and may motivate purchase likelihood. We conducted two consumer-assisted marketing 
experiments each entitled "The Ideal Fresh Blueberry" to measure favorability of various blueberry attributes to guide research objectives, breeding priorities, and marketing messages that may characterize a superior blueberry experience to be delivered to the consumer.

\section{Materials and Methods}

Rule developing experimentation (RDE), developed by Moskowitz Jacobs Inc. in cooperation with the Wharton School of Business at the University of Pennsylvania, Philadelphia, PA, and implemented with the IdeaMap $^{\circledR}$ interface, was used to identify consumer blueberry preferences. RDE is an experimental design used to assay the potential consumer interest of products comprised of new and different combinations of specific features. Many features may be tested in an analysis by combining specifics from different categories that describe a product. The consumer responds by indicating their interest (on a 9-point scale) to each unique product feature package. Using regression analysis, the independent variables (product specifications) are related to the dependent variable (consumer interest). IdeaMap ${ }^{\circledR}$ technology uses modified conjoint analysis to determine the effect of a single independent variable when presented in multiple combinations with other independent variables in a matric setup in which product "concepts" and their constituent elements are assigned a binary rating of either 0 (consumer disinterest, rating of 1 to 6) or 100 (consumer interest, rating of 7 to 9) (Moskowitz, 2012; Moskowitz et al., 2006; Moskowitz and Gofman, 2007). This methodology was previously used by Colquhoun et al. (2012) and Levin et al. (2012) to evaluate consumerdesired traits in fresh strawberry and flowers, respectively. Setup of the two blueberry experiments and statistical analyses of the data are summarized below.

Two studies entitled "The Ideal Fresh Blueberry" were conducted: the first in Oct. 2011 and a second in June 2013. The subjects for the surveys were recruited independently through Panel Direct Online ( $<$ http://www.paneldirectonline.com $>)$, a division of Focus Forward, LLC $(<\mathrm{http}: / / \mathrm{www}$. focusfwd.com $>$ ). Recruits logging into the study were initially asked their gender and ethnicity. We chose to recruit an approximate $50 / 50$ split between male and female consumers because it closely approximates the likelihood of blueberry purchase based on gender as reported by Fresh Trends (2012, 2013). A total of 306 and 300 subjects completed the first and second "The Ideal Fresh Blueberry" studies, respectively.

In each study, six categories of blueberry traits were tested: firmness, texture, size, color, flavor, and human nutrition. These categories are major breeding objectives in the University of Florida blueberry breeding program. The categories were further divided into six specific elements for a total of 36 independent elements listed in Table 1.
Responses from the first study were used to grammatically modify a few of the elements in the second study for descriptive clarity. In both studies, each subject was introduced to the study by a welcome screen and was sequentially asked to rate their interest in fresh blueberry experiences consisting of a combination of three to four randomized elements (each from a different category) on a 9 -point scale $(1=$ not at all likely, $9=$ very likely). In the second study, the interest rating question was reworded to test likelihood of purchase rather than just favorability (Fig. 1). Subjects responded to 48 of these permutated element combinations and 10 demographic questions before completing the study. Unless otherwise indicated, the data tables presented in this article are from the 2013 study.

Regression modeling was used to determine which elements drive liking/disliking. Regression modeling related the independent variables (elements) to the dependent variable (rating) and assigned numerical values to each element using an additive equation of the form:

$$
\begin{aligned}
\text { Rating }= & \mathrm{k}_{0}+\mathrm{k}_{1}(\text { element A1 }) \\
& +\mathrm{k}_{2}(\text { element A2 })+\ldots \\
& +\mathrm{k}_{36}(\text { element F6 }),
\end{aligned}
$$

where $\mathrm{k}_{0}$ is the additive constant and $\mathrm{k}_{1}$ to $\mathrm{k}_{36}$ are coefficients that correspond to interest values $(\mathrm{InV})$ of elements 1 to 36, respectively. This equation is calculated per respondent. The value $\mathrm{k}_{0}$ is the sum of all the respondents' ratings divided by the number of questions rated. The average of $\mathrm{k}_{0}$ for all respondents is a representative baseline control called an additive constant and sets the benchmark for the impact of individual elements on consumer preference. The constant represents interest of subjects responding to the concept of an "ideal fresh blueberry" without influence of the subsequent elements. The averages of the coefficients of this equation are used to assign values to elements in the study as a whole or within segments. The InV of a particular element is shown as the difference respective to the constant to show incremental or decremental effects on overall liking (Moskowitz et al., 2006).

Market segmentation is an important concept that assumes heterogeneity in consumers' preferences. There are two approaches that can be used to identify market segments, a priori segmentation and post hoc segmentation. In a priori segmentation, consumers are grouped by reported demographic differences such as gender, ethnicity, and income. In post hoc segmentation, consumers score aspects of product variables and are then clustered into groups with similar product preferences (Green and Krieger, 1991). Both approaches to market segmentation were explored with the data.

K-cluster analysis was applied to the matrices of 36 columns (one column per element) and 300 rows (one row per respondent) to identify post hoc segments within the surveyed populations and was performed in
SYSTAT 13 (Systat Software, Chicago, IL). Clusters comprise a fraction of the total population and separate the total population by differing impact values regarding the elements rated. Within a cluster, the strongest performing elements (positive or negative) are shared (Moskowitz, 2012). The two studies were compared for significant differences (Student's $t$ test, $\alpha=0.005$ ) in reported InVs between the two respondent pools in JMP Pro 10 (SAS Institute Inc., Cary, NC). The reproducibility of population segmentation was analyzed by testing for significant differences between top-most and bottommost defining elements in corresponding segments.

\section{Results}

The goal of this experiment was to determine consumer perceptions of the ideal fresh blueberry experience. Using RDE, we assayed sensory and psychological components of blueberry consumption that humans perceive as favorable or unfavorable by assaying how individual elements affected likelihood of purchase. Table 1 lists the six categories tested (firmness, texture, size, color, flavor, and nutrition), each comprised of six more specific elements. Experimental design of the descriptive elements was tested in the preliminary 2011 study. The study was replicated in 2013 with a separately recruited respondent pool and with six elements slightly reworded or completely changed for enhanced descriptive clarity. In each study, subjects rated 48 permutated combinations of three to four elements (Fig. 1) and answered 10 demographic questions (Fig. 2).

The baseline constant for both studies was similar at 55 and 41 for 2011 and 2013, respectively. Overall, responses to the same elements were not significantly different between the two respondent pools (Table 1). Six elements were altered from the 2011 study to the 2013 study for improved description of the sensory experience being portrayed. Element A1 was changed from "Bite down on a berry...hear a loud crunch" to "Crispy berry...pops in your mouth" to more adequately describe the experience of eating a crisp berry with a grape-like pop. The respondent reactions to the wording of these two elements were significantly different $(P<0.005)$. Interest values went from a sample average of -6 for "crunchy berries" in the first study to +4 for "crispy berries." Similarly, a change in element D4 from the original "Blueberries with a waxy white coating" to "Blueberries with a soft, cloudy white coating" generated a significant change in $\operatorname{InV}(P<0.005)$ from a sample average of -12 to -2 . The clarification "like a grape" was added to element A4, "Firm with no give," element B6 was changed from "Not mealy... at all" to "Light and airy," C1 from "Plump and round" to "The biggest berries you've ever seen," and C6 from "Medium size" to "Medium, dime-sized," all with no significant difference in InV. 
Table 1. Experimental design of categories (A-F) and individual elements (1-6) of each category for the 2013 "The Ideal Fresh Blueberry" consumer perception study. ${ }^{2}$

\begin{tabular}{lrrrr}
\hline & 2011 study & & \\
\hline Base size & Base size & & \\
Constant & & 302 & Constant & 300 \\
& & 55 & InV & 41 \\
InV & &
\end{tabular}

$\begin{array}{ll}\text { A1 } & \text { Bite down on berry...hear a loud crunch } \\ \text { A2 } & \text { Mushy...melts in the mouth } \\ \text { A3 } & \text { A soft berry } \\ \text { A4 } & \text { Firm with no give } \\ \text { A5 } & \text { Thin skin that melts away } \\ \text { A6 } & \text { Tough chewy skin }\end{array}$

\section{B1}

$\mathrm{B} 2$

B3

B4

B5

B6

$\begin{array}{ll}\text { C1 } & \text { Plump and round } \\ \text { C2 } & \text { Petite berries } \\ \text { C3 } & \text { Tiny...to eat bunches at a time } \\ \text { C4 } & \text { As big as a large marble } \\ \text { C5 } & \text { Small...pea sized } \\ \text { C6 } & \text { Medium size }\end{array}$

D1 Deep blue, almost black color

D2 Berries that are a shade of light blue

D3 Berries that are bright blue in color

D4 Blueberries with a waxy white coating

D5 Berries are dark blue throughout

D6 Dark blue outside...pale inside

$\begin{array}{ll}\text { E1 } & \text { Fruity flavor } \\ \text { E2 } & \text { Bold and intense blueberry flavor } \\ \text { E3 } & \text { Complex flavor with a hint of bitter } \\ \text { E4 } & \text { So sweet...no sugar needed } \\ \text { E5 } & \text { Tart berry that wakes the taste buds } \\ \text { E6 } & \text { Mild flavor...but compliments well }\end{array}$

\begin{tabular}{ll} 
F1 & Full of antioxidants \\
F2 & No fat...no cholesterol \\
F3 & High in vitamin C \\
F4 & A rich source of dietary fiber \\
F5 & Organic berries \\
F6 & A low-carbohydrate source of nutrients \\
\hline
\end{tabular}

Category A: Berry Firmness

$\begin{array}{rlrr}-6 & \text { Crispy berry...pops in your mouth } & 4 & * \\ -8 & \text { Mushy...melts in your mouth } & -14 & \text { NS } \\ -5 & \text { A soft berry } & -5 & \text { NS } \\ -8 & \text { Firm with no give, like a grape } & -2 & \text { NS } \\ -1 & \text { Thin skin that melts away } & -2 & \text { NS } \\ -19 & \text { Tough, chewy skin } & -17 & \text { NS }\end{array}$

Category B: Berry texture

$\begin{array}{rlrr}7 & \text { Smooth texture without seeds } & 2 & \text { NS } \\ -21 & \text { Lots of seeds, a bit of grit } & -19 & \text { NS } \\ 10 & \text { Full of juice } & 7 & \text { NS } \\ -5 & \text { Meaty, not juicy } & -9 & \text { NS } \\ -17 & \text { Mealy, pasty, and dry } & -23 & \text { NS } \\ -1 & \text { Light and airy } & 1 & \text { NS }\end{array}$

\begin{tabular}{clrl}
\multicolumn{2}{c}{ Category C: Berry size } & & \\
3 & The biggest berries you've ever seen & 5 & NS \\
-4 & Petite berries & 0 & NS \\
-5 & Tiny...to eat bunches at a time & -3 & NS \\
0 & As big as a large marble & 5 & NS \\
-7 & Small, pea-sized & -4 & NS \\
-1 & Medium, dime-sized & 4 & NS
\end{tabular}

Category D: Berry color

$\begin{array}{rlrc}2 & \text { Deep blue, almost black color } & 5 & \text { NS } \\ -2 & \text { Berries that are a shade of light blue } & -1 & \text { NS } \\ -1 & \text { Berries that are bright blue in color } & 3 & \text { NS } \\ -12 & \text { Blueberries with a soft, cloudy white coating } & -2 & * \\ 3 & \text { Berries are dark blue throughout } & 6 & \text { NS } \\ 1 & \text { Dark blue outside, pale inside } & 3 & \text { NS }\end{array}$

Category E: Berry flavor

$\begin{array}{rlrr}6 & \text { Fruity flavor } & 6 & \text { NS } \\ 7 & \text { Bold and intense blueberry flavor } & 11 & \text { NS } \\ -9 & \text { Complex flavor with a hint of bitter } & -6 & \text { NS } \\ 10 & \text { So sweet, no sugar needed } & 13 & \text { NS } \\ 1 & \text { Tart berry that wakes the taste buds } & -3 & \text { NS } \\ 1 & \text { Mild flavor, but compliments well } & -3 & \text { NS }\end{array}$

Category F: Human nutrition

\begin{tabular}{|c|c|c|c|}
\hline 6 & Full of antioxidants & 7 & NS \\
\hline 1 & No fat, no cholesterol & 0 & NS \\
\hline 6 & High in vitamin $\mathrm{C}$ & 2 & NS \\
\hline 6 & A rich source of dietary fiber & 2 & NS \\
\hline 5 & Organic berries & 5 & NS \\
\hline 0 & A low-carbohydrate source of nutrients & -1 & NS \\
\hline
\end{tabular}

${ }^{2}$ Each category represents an aspect of blueberries such as: berry firmness, texture, size, color, flavor, and human nutrition. Within each category are six descriptive elements related to the category, resulting in a total of 36 individual elements. Interest values (InV) for elements measured by "The Ideal Fresh Blueberry" consumer-preference studies. InV compare the tested elements and are relative to the baseline constant value (the percentage of subjects that would respond favorably to "The Ideal Fresh Blueberry" even if no elements were presented) of 55 or 41 (2011 and 2013, respectively). A high InV indicates a positive effect on consumer liking; a low InV indicates a negative effect on consumer liking. InVs close to zero may be considered neutral on consumer affect. The two studies were compared for significant differences (Student's $t$ test, $\alpha=0.005$ ) in reported interest values between the two respondent pools. Only elements A1, A4, B6, C1, C6, and D4 were changed between studies. NS = nonsignificant.

Among both sample populations, the two elements that scored highest in consumer favorability by InV (Table 2) were the flavor elements "so sweet...no sugar added" and "bold and intense blueberry flavor." Also among the five highest InVs in the final study were three elements from three separate categories: "full of juice," "full of antioxidants," and "berries are dark blue throughout." In contrast, five quality traits most detrimental to purchase were from the berry firmness and texture categories, including "mealy, pasty, and dry," "lots of seeds, a bit of grit," "tough chewy skin," "mushy, melts in your mouth," and "meaty, not juicy." In general, the elements with the highest and lowest InVs were consistent between the two studies (Tables 1-3). Because the final study was a superior test of the complete set of blueberry traits, we present the data from the 2013 study in detail.

Of the 300 subjects who completed the final study, 99\% had previously purchased blueberries in their lifetime, and $96 \%$ had purchased fresh blueberries in the past year. The data were grouped by reported gender, age, ethnicity, income groups, and relationship status (Table 3) to see whether any a priori market segments could be distinguished (Green and Krieger, 1991). Flavor elements remained among the top two most favorable berry qualities in a majority of the groups, whereas tactile elements of seediness, chewiness, mealiness, or mushiness had the strongest potential to decrease purchase likelihood. 


\section{Mealy, pasty and dry \\ Berries that are a light shade of blue \\ So sweet, no sugar needed \\ No fat, no cholesterol}

How likely are you to purchase fresh blueberries of this type?

\section{1) $20 \begin{array}{llllllll} & 4 & 5 & 6 & 7 & 8 & 9\end{array}$}

Not at all likely <--- 123456789 ---> Very likely

Fig. 1. An example of a blueberry element combination presented to a survey subject. The subject responded to the interest rating question by indicating likelihood of purchase of this combination of elements.
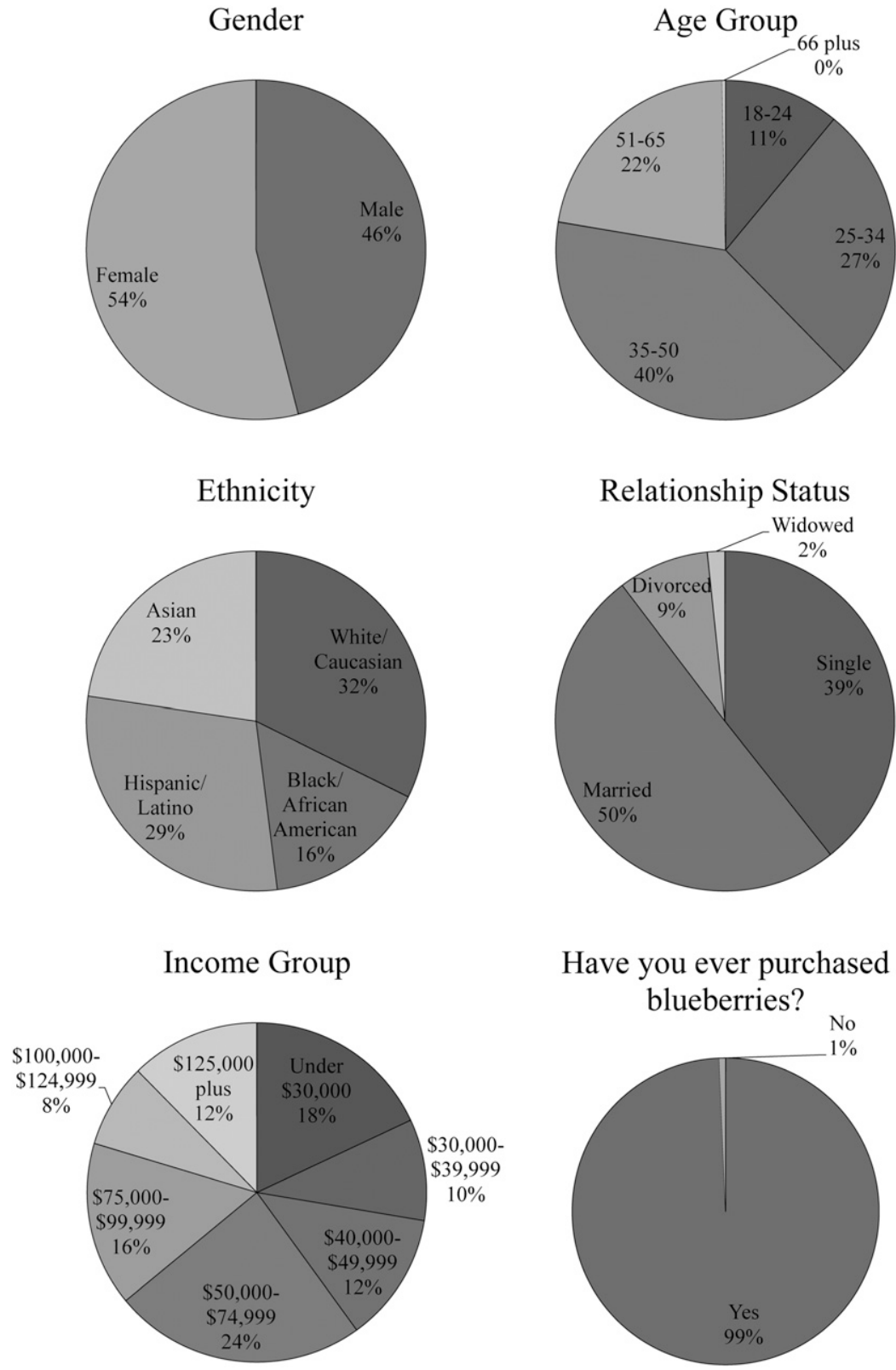

Fig. 2. Reported demographic sections of the "Ideal Fresh Blueberry" consumer perception survey (total subjects $=300)$

There was no difference between the elements with the two highest and lowest InVs when the data were grouped by gender

(Table 3). Females were more interested in the concept of the ideal fresh blueberry than males (constant $=44$ and 37, respectively).
Both groups shared some of the most impactful high and low elements (Supplemental Table 1); however, males were more interested in fruity flavor and deep blue color, whereas females were more responsive to juicy berries as big as a large marble. Females responded more negatively to a seedy blueberry than males (InV $=-25$, female; -13 , male). Additionally, females in this study were strongly opposed to tart and bitter berries.

The only age group to deviate from the flavor-interest norm was the 25- to 34-year age group, who were most driven to purchase by "medium, dime-sized" and "organic berries" (Table 3 ). The youngest group (18 to 24 years) was the most interested in blueberries (constant $=56$, followed by the oldest age group (constant $=50$ ), whereas the 35- to 50-year age group was least interested in the topic (constant $=28$ ). Although they were most interested in the ideal fresh blueberry, the youngest group was not particularly interested in many specified aspects of blueberries listed in the study. The most impactful positive element for this age group was the element of bold and intense blueberry flavor. The 35- to 50-year age group was the only one that had a high InV for crispness, large size, fruity flavor, and antioxidants (Supplemental Table 2). Although organic berries were positive among those 25 to 34 years and 35 to 50 years of age, they elicited a negative response from those in the 51- to 65-year group.

When compared by reported ethnic group (Table 3), tactile elements reappeared consistently among the most unfavorable qualities for all groups. The Hispanic/Latino group was most responsive to "fruity flavor" and the Asian group also responded positively to "full of juice." The white/Caucasian group was the only group to favor bright blue and dark blue elements (Supplemental Table 3). The only uniquely impactful element in the black/African American group was a strongly negative InV for "Firm with no give, like a grape."

When the data were sorted by income, the groups with highest overall interest in the ideal fresh blueberry were those reporting earnings of $\$ 100,000$ to $\$ 124,999$ and under $\$ 30,000$ (Table 3). One of the top two highest scoring (InV) elements from the whole study was a top purchase influencer in each income group other than for subjects who reported earnings of $\$ 100,000$ to $\$ 124,999$. This group was most receptive to juicy, organic berries. Other elements besides the common flavor traits that revealed high InVs included crispy berries for the $\$ 40,000$ to $\$ 49,999$ group, big berries for the $\$ 75,000$ to $\$ 99,999$ group, and juicy berries for the $\$ 125,000+$ group. The group with earnings of $\$ 50,000$ to $\$ 74,999$ was the only group to show interest in soft berries, a sensory descriptor that most groups found to be strongly negative (Supplemental Table 4). The group with earnings of $\$ 30,000$ to $\$ 39,999$ was the only group to respond favorably to petite berries. Those earning $\$ 50,000$ to $\$ 74,999$ were the only ones to 
Table 2. Element interest values (InV) for all 300 subjects of the "The Ideal Fresh Blueberry" consumer preference study are ordered from highest to lowest. ${ }^{z}$

\begin{tabular}{|c|c|c|}
\hline & Element & $\operatorname{InV}$ \\
\hline$\overline{\mathrm{E} 4}$ & So sweet, no sugar needed & $\overline{13}$ \\
\hline E2 & Bold and intense blueberry flavor & 11 \\
\hline B3 & Full of juice & \\
\hline F1 & Full of antioxidants & \\
\hline D5 & Berries are dark blue throughout & 6 \\
\hline E1 & Fruity flavor & \\
\hline $\mathrm{C} 1$ & The biggest berries you've ever seen & \\
\hline $\mathrm{C} 4$ & As big as a large marble & \\
\hline D1 & Deep blue, almost black color & \\
\hline F5 & Organic berries & \\
\hline A1 & Crispy berry...pops in your mouth & \\
\hline C6 & Medium, dime-sized & \\
\hline D3 & Berries that are bright blue in color & \\
\hline D6 & Dark blue outside, pale inside & \\
\hline B1 & Smooth texture without seeds & \\
\hline F3 & High in vitamin $\mathrm{C}$ & \\
\hline F4 & A rich source of dietary fiber & \\
\hline B6 & Light and airy & \\
\hline $\mathrm{C} 2$ & Petite berries & \\
\hline $\mathrm{F} 2$ & No fat, no cholesterol & U \\
\hline D2 & Berries that are a shade of light blue & -1 \\
\hline F6 & A low-carbohydrate source of nutrients & -1 \\
\hline A4 & Firm with no give, like a grape & -2 \\
\hline A5 & Thin skin that melts away & -2 \\
\hline D4 & Blueberries with a soft, cloudy white coating & \\
\hline $\mathrm{C} 3$ & Tiny...to eat bunches at a time & - \\
\hline E5 & Tart berry that wakes the taste buds & - \\
\hline E6 & Mild flavor, but compliments well & \\
\hline C5 & Small, pea-sized & -4 \\
\hline A3 & A soft berry & -5 \\
\hline E3 & Complex flavor with a hint of bitter & \\
\hline B4 & Meaty, not juicy & -9 \\
\hline A2 & Mushy...melts in your mouth & -14 \\
\hline A6 & Tough, chewy skin & -17 \\
\hline B2 & Lots of seeds, a bit of grit & -19 \\
\hline B5 & Mealy, pasty, and dry & -23 \\
\hline
\end{tabular}

${ }^{\mathrm{z}}$ InV are relative to the baseline constant value of 41 (the percentage of subjects that would respond favorably to "The Ideal Fresh Blueberry" even if no elements were presented) to compare the tested elements.

be interested in "tiny... to eat bunches at a time"; all other groups responded negatively to this size descriptor. A berry that is dark blue throughout received positive interest from the $\$ 75,000$ to $\$ 99,999$ group, where all other income groups responded neutrally to this element. The $\$ 50,000$ to $\$ 74,999$ group responded favorably to the concept of blueberries with a dark blue outside and a pale inside.

The single, married, and separated/divorced groups only differed in that (Table 3 ) the divorced/separated group was partial toward "berries that are a light shade of blue" but disliked "petite berries" (Table 3; Supplemental Table 5).

Respondents were asked to classify their neighborhoods as rural, suburban, or urban. Study interest as indicated by the constant value was the same between rural and urban respondents (constant $=37$ and 36, respectively) (Table 3 ). The suburban group was more interested in the blueberries in general (constant $=45$ ). The rural group was most interested in fruity flavored blueberries with a dark blue outside and pale inside; it was the only group in this classification scheme to respond favorably to this element (Supplemental Table 6).

Respondents reported the region of the United States in which they resided: Northeast
(NE), Northwest (NW), Midwest (MW), Southeast (SE), or Southwest (SW). Subjects in the SE and SW were most interested in blueberries (constant $=56$ and 53, respectively), whereas the NW and MW had the lowest constant values (constant $=24$ and 27, respectively) (Table 3 ). The NE was the only region interested in large, crisp berries. The SW responded favorably to the elements "full of juice" and "full of antioxidants." The SE only responded positively to "so sweet, no sugar needed" (Supplemental Table 7).

Purchase location provided another variable for classification of blueberry consumers. Most consumers purchased their blueberries at their local commercial grocery store $(\mathrm{n}=126)$ or at a supercenter chain store $(\mathrm{n}=101)$ (Table 3). A smaller subset of respondents reported purchasing blueberries from a farmers market $(n=52)$. One percent to $2 \%$ of respondents reported purchasing berries at a roadside stand, mom and pop grocery store, u-pick, or other. The farmers' market shoppers had a much higher interest in the general concept of blueberries than the store-bought groups (constant $=61$ vs. 38 and $34)$. Given such a high constant value, no elements stood out as having a significant impact (Supplemental Table 8).

Two independent post hoc market segments (Green and Krieger, 1991) from "The
Ideal Fresh Blueberry" were defined using $\mathrm{K}$-cluster analysis. K-cluster analyses of the two studies resulted in similar segments when $K=2$ (Table 4 ). In either study, the interest of one segment was driven by the perceived flavor experience and the other by recognized health benefits associated with consuming blueberries. However, on further segmentation $(K=3, K=4)$, the studies diverged in agreement. Therefore, we only report on the reproducible two-segment analysis. The larger first segment, composed of $61 \%$ of subjects surveyed $(n=184)$, had a slightly lower constant (39) than the study average (41). Elements from the flavor category (Table 1, Category E) scored very highly within this segment of the study with respondents indicating blueberries of sweet, bold, and fruity attributes as most desirable. The second segment $(\mathrm{n}=116)$ had a constant value slightly higher (43) than the average and scored elements from the human nutrition category (Table 1, Category F) most favorably. This group wanted to purchase organic berries packed with antioxidants, fiber, and vitamin C. Both segments were uniformly demotivated to purchase blueberries that were seedy, mealy, chewy, and dry.

The reported demographics of the individual respondents falling into either segment are shown in Figure 3. Because the "flavor" segment was the larger of the two, there were generally more respondents from each demographic category in this segment. This being said, respondents of both segments had similar distributions of age, neighborhood classification, and blueberry purchase locations. The "health" segment was evenly represented by males and females, but the "flavor" segment was $57 \%$ female and captured $65 \%$ of total female respondents of the study. The white/Caucasian group made up the largest portion of the "flavor" segment with $70 \%$ of respondents from this group clustering into this segment. Asians made up a larger proportion of the "health" segment than the "flavor" segment $(28 \%$ vs. $20 \%$, respectively). The Hispanic and black/African American ethnic groups made up similar proportions of both segments. A higher proportion of respondents who reported making less than $\$ 30,000$ a year were grouped into the "health" segment.

\section{Discussion}

Because the blueberry buying decision and blueberry sensory and psychological experiences are composed of a complex and diverse set of traits with many different variables contributing to consumer preference, breeders have many avenues through which to attempt to improve their product. By assaying consumer preference for blueberry traits, breeders are better equipped to determine which aspects of blueberries result in the highest consumer favorability leading to purchase (and repetition of this behavior). With $50 \%$ of consumers having purchased blueberries in 2010, 2011, and 2012, and of 


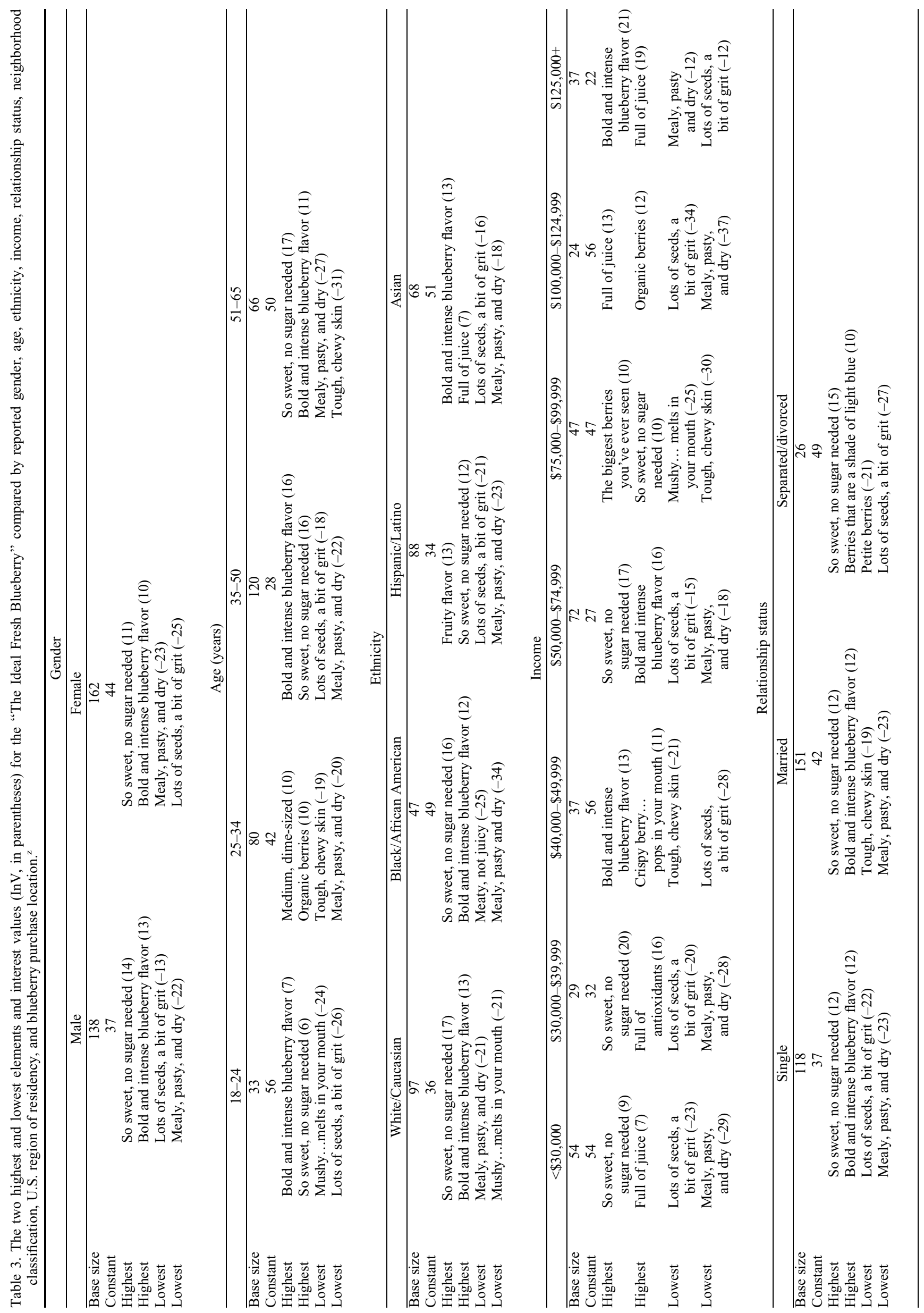




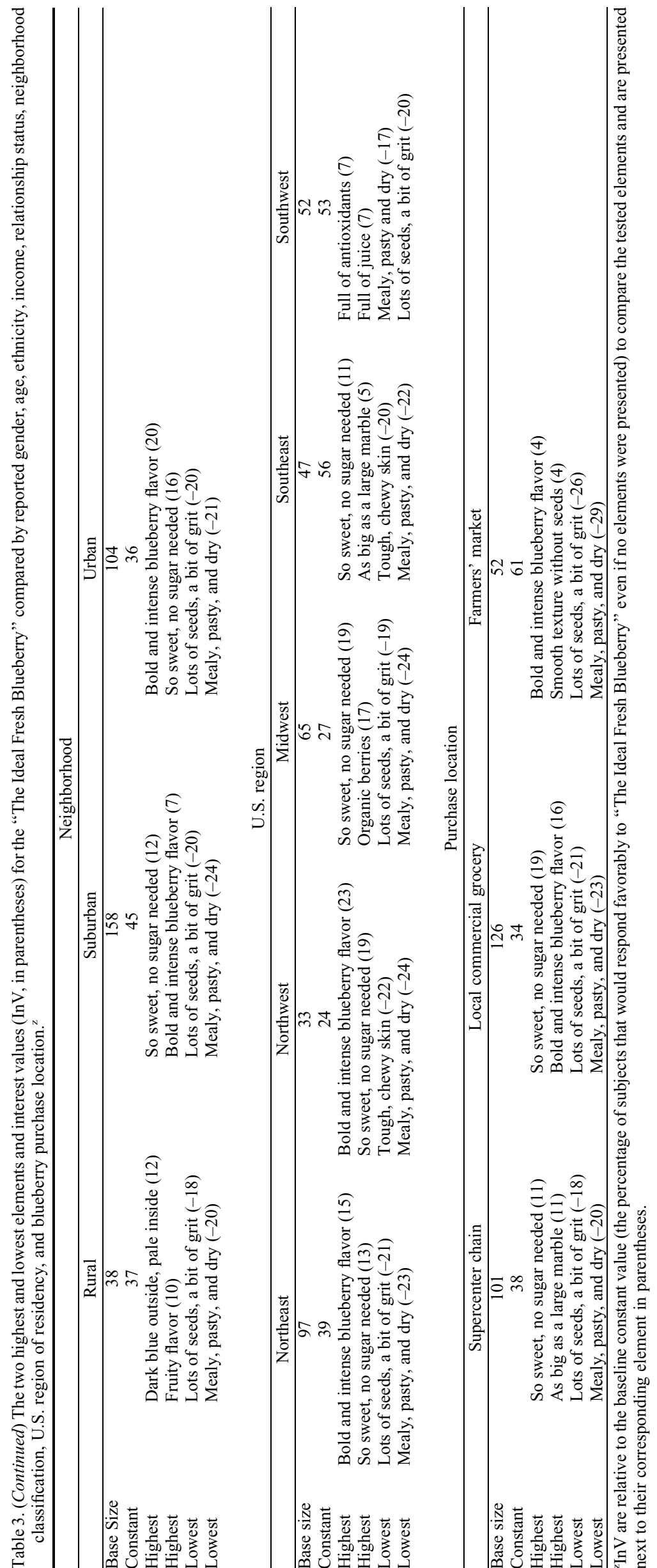

that $15 \%$ repeat consumers, there exists plenty of room for market expansion (Brazelton, 2013; Fresh Trends, 2011, 2012, 2013).

The development of cogent phrases to describe aspects of the blueberry experience is a critical step in the construction of an IdeaMap study. This is underscored by the significantly differing responses to particular elements when reworded between the initial and final studies in this article (Table 1). Crispness is a novel blueberry texture that is present in few commercial cultivars, including 'Bluecrisp', 'Sweetcrisp', 'Reveille', 'Dolores', 'Hortblue Poppins', and 'FL98325' (marketed under the trademarked name Indigocrisp) (Clark and Finn, 2010; Okie, 1999; Scalzo et al., 2009). On initial mastication of these blueberries, an audible, grape-like pop occurs on breaking the skin. However, the words used to describe this potentially unfamiliar blueberry trait affect the appeal of the hypothetical sensory experience. Respondents were unfavorable to the scenario "Bite down on berry...hear a loud crunch." However, "Crispy berry...pops in your mouth" induced a positive response from test subjects. When the clarification "...like a grape" was added to element A4 "Firm with no give..." in the 2013 study, a small but statistically insignificant increase in response occurred. This element scored low negative InVs in both studies. This information is important for the marketing potential of these novel berries. Use of particular words may confuse the consumer and lead to rejection of the product, whereas others may garner genuine purchasing interest.

The lexicon used to describe the "bloom" of a blueberry fruit also presented difficulty. The bloom is a naturally occurring, fragile coat of wax that reflects light off the fruit, causing dark blueberry fruit to appear bright blue to powdery light blue in color. Different blueberry cultivars vary in the amount and type of wax deposited on the outer surface of the skin, resulting in variations in blueness (Albrigo et al., 1980; Retamales et al., 2014). In a consumer sensory panel by Saftner et al. (2008), a regression analysis of individual blueberry color values and visual appeal resulted in a weak but significant relationship between consumer preference and lighter blue fruit. This trait was described in the first IdeaMap study as "blueberries with a waxy white coating" and scored an InV of -12 (Table 1). On reflection, it was agreed on that the element as such did not communicate this blueberry characteristic adequately and was modified to "blueberries with a soft, cloudy white coating." With the new wording, the element jumped from strongly negative to neutral $(\mathrm{InV}=-2)$. This information suggests that blueberry consumers would not be receptive to the verbal communication of this trait's botanical jargon. Consumers motivated to purchase by color distinctions will simply make this decision visually.

A possible explanation for the variation of interest in relation to different descriptions of crispness and bloom may have to do 
Table 4. K-cluster analysis $(K=2)$ of the 300 subjects who completed "The Ideal Fresh Blueberry" survey revealed two segments of current or potential fresh blueberry purchasers that responded highly favorably to different groups of blueberry attributes. ${ }^{z}$

\begin{tabular}{|c|c|c|c|}
\hline & & $\begin{array}{l}\text { Segment } 1 \\
\text { "Flavor" }\end{array}$ & $\begin{array}{l}\text { Segment } 2 \\
\text { "Health" }\end{array}$ \\
\hline & Base size & 184 & 116 \\
\hline & Constant & 39 & 43 \\
\hline$\overline{\mathrm{A} 1}$ & Crispy berry...pops in your mouth & 3 & 5 \\
\hline A2 & Mushy...melts in your mouth & -17 & -8 \\
\hline A3 & A soft berry & -7 & -1 \\
\hline A4 & Firm with no give, like a grape & -2 & -2 \\
\hline A5 & Thin skin that melts away & -6 & 4 \\
\hline A6 & Tough, chewy skin & -21 & -10 \\
\hline B1 & Smooth texture without seeds & 7 & -5 \\
\hline B2 & Lots of seeds, a bit of grit & -20 & -19 \\
\hline B3 & Full of juice & 5 & 11 \\
\hline B4 & Meaty, not juicy & -2 & -20 \\
\hline B5 & Mealy, pasty, and dry & -23 & -23 \\
\hline B6 & Light and airy & 0 & 2 \\
\hline $\mathrm{C} 1$ & The biggest berries you've ever seen & 7 & 2 \\
\hline $\mathrm{C} 2$ & Petite berries & 6 & -9 \\
\hline $\mathrm{C} 3$ & Tiny...to eat bunches at a time & 2 & -11 \\
\hline $\mathrm{C} 4$ & As big as a large marble & 8 & -1 \\
\hline $\mathrm{C} 5$ & Small, pea-sized & 0 & -11 \\
\hline C6 & Medium, dime-sized & 9 & -5 \\
\hline D1 & Deep blue, almost black color & 6 & 3 \\
\hline D2 & Berries that are a shade of light blue & -1 & -1 \\
\hline D3 & Berries that are bright blue in color & 3 & 2 \\
\hline D4 & Blueberries with a soft, cloudy white coating & -3 & -1 \\
\hline D5 & Berries are dark blue throughout & 8 & 2 \\
\hline D6 & Dark blue outside, pale inside & 1 & 7 \\
\hline E1 & Fruity flavor & $10 *$ & -1 \\
\hline E2 & Bold and intense blueberry flavor & $16^{*}$ & 4 \\
\hline E3 & Complex flavor with a hint of bitter & 0 & -15 \\
\hline E4 & So sweet, no sugar needed & $22 *$ & -3 \\
\hline E5 & Tart berry that wakes the taste buds & 2 & -10 \\
\hline E6 & Mild flavor, but compliments well & 1 & -10 \\
\hline F1 & Full of antioxidants & 1 & 15 \\
\hline F2 & No fat, no cholesterol & -4 & 6 \\
\hline F3 & High in vitamin $\mathrm{C}$ & -4 & $11^{*}$ \\
\hline F4 & A rich source of dietary fiber & -5 & $13^{*}$ \\
\hline F5 & Organic berries & 1 & $11 *$ \\
\hline F6 & A low-carbohydrate source of nutrients & -7 & 8 \\
\hline
\end{tabular}

${ }^{\mathrm{z}}$ The three highest scoring elements in each segment are denoted by *.

with the lack of general consumer familiarity with these traits. A lack of exposure to crisp blueberries or to the attribute of blueberry bloom may leave the subject confused and could reduce the subject's capacity for elaborate processing (Park and Lessig, 1981).

In contrast, three other element changes resulted in no significant variation in subject responses. The texture element "not mealy at all," which garnered a fairly neutral InV of -1 in the first study, was replaced with "light and airy." This element also failed to have a positive or negative impact on respondent interest with a comparably neutral InV of +1 . Adding the visual "dime-sized" to the medium berry element increased the InV 5 points but was statistically insignificant. "The biggest berries you've ever seen" was substituted for the size element "plump and round" to create more distinction between the elements of this category and resulted in an insignificant $\mathrm{InV}$ increase of 2 .

The consumer preference studies indicated that flavor may be the most influential category affecting human preference of fresh blueberries. Sweetness, flavor intensity, "blueberry-ness," and fruitiness were all correlated to high consumer likelihood of purchase $(\mathrm{InV})$ in the sample surveyed as a whole and in nearly every classification dissection (Table 3). These results are similar to Saftner et al. (2008), in which overall eating quality was most highly correlated with flavor acceptability and blueberry-like flavor intensity in consumer panels. Subjects in this consumer preference study responded most negatively to mealy, seedy, mushy blueberry attributes, which were also found to be very important to eating quality in the Saftner et al. (2008) sensory acceptability study.

By segregating the data by the respondents' answers to the classification questions, we can further understand the blueberry desires of more specific groups of the population. Within a particular classification frame, some groups are much more interested in blueberries than others. The most defining classification questions were ethnicity, income, neighborhood, region, and purchase location. There were few differences between genders, ages, or relationship status.

Those living in rural areas and those reporting income above $\$ 100,000$ were the only two classification groups to respond favorably to a blueberry with a dark blue outside and a pale inside. This suggests that those in rural America have actually observed the inside of a fresh blueberry, which is not blue throughout as many would speculate and as the urban group found favorable (Supplemental Table 6). Those making more than $\$ 100,000$ were the most likely income group to purchase blueberries and therefore also have increased exposure to the product (Fresh Trends, 2011, 2012, 2013). Additionally, from 3 years of The Packer's Fresh Trends $(2011,2012,2013)$ data, the propensity to purchase blueberries increases relative to income, with those making $\$ 100,000+$ twice as likely to purchase blueberries as those making less than $\$ 25,000$. Furthermore, consumers in the northeastern United States are more likely to purchase blueberries than any other region (Fresh Trends, 2011, 2012, 2013).

Although a priori segmentation offered some insight into demographic variation of the ideal fresh blueberry, the observations were not much different from observing the population as a whole. Once the total panel was divided into two post hoc segments using cluster analysis, two patterns in preference became evident (Table 4). Segment 1, the largest segment comprised of 184 subjects, favored the blueberry flavor elements "So sweet...no sugar added," "Bold and intense blueberry flavor," and "Fruity flavor." Above all other sensory experiences, desirable flavor had the most positive purchasing power. The smaller Segment 2 (116 subjects) had likely been influenced by the media coverage of health benefits that has helped to popularize blueberries. This "health" segment converged on aspects relating to antioxidants, fiber, vitamin $\mathrm{C}$, and organic production. Antioxidants such as anthocyanins are found in high amounts in blueberry fruit and have been correlated with beneficial health effects in numerous biological systems including immunology, ophthalmology, cardiology, neurology, metabolism, and inflammation (Cassidy et al., 2013; Fan et al., 2012; Heim et al., 2012; Krikorian et al., 2010; Li et al., 2013; Liu et al., 2012; McAnulty et al., 2011; Shukitt-Hale, 2012; Tipton et al., 2013; Yousef et al., 2013). The number of consumers who purchased organically produced blueberries doubled from $6 \%$ in 2010 to $11 \%$ in 2011 (Fresh Trends, 2011, 2012, 2013) reinforcing the influence of Segment 2's preference for organic production on actual consumption.

These data suggest flavor components elicited the highest favor among blueberry sensory components in the larger population segment with nutrient-based marketing as an important psychological driver. Whether the respondents' potential purchases were driven by sensory experience or the perceived health benefits, both segments of the study were in agreement that seedy, tough, and dry berry characteristics had a very negative impact on the likelihood of purchase. These clusterderived segments present an opportunity to improve the blueberry market as a whole by providing focus for different points in the 

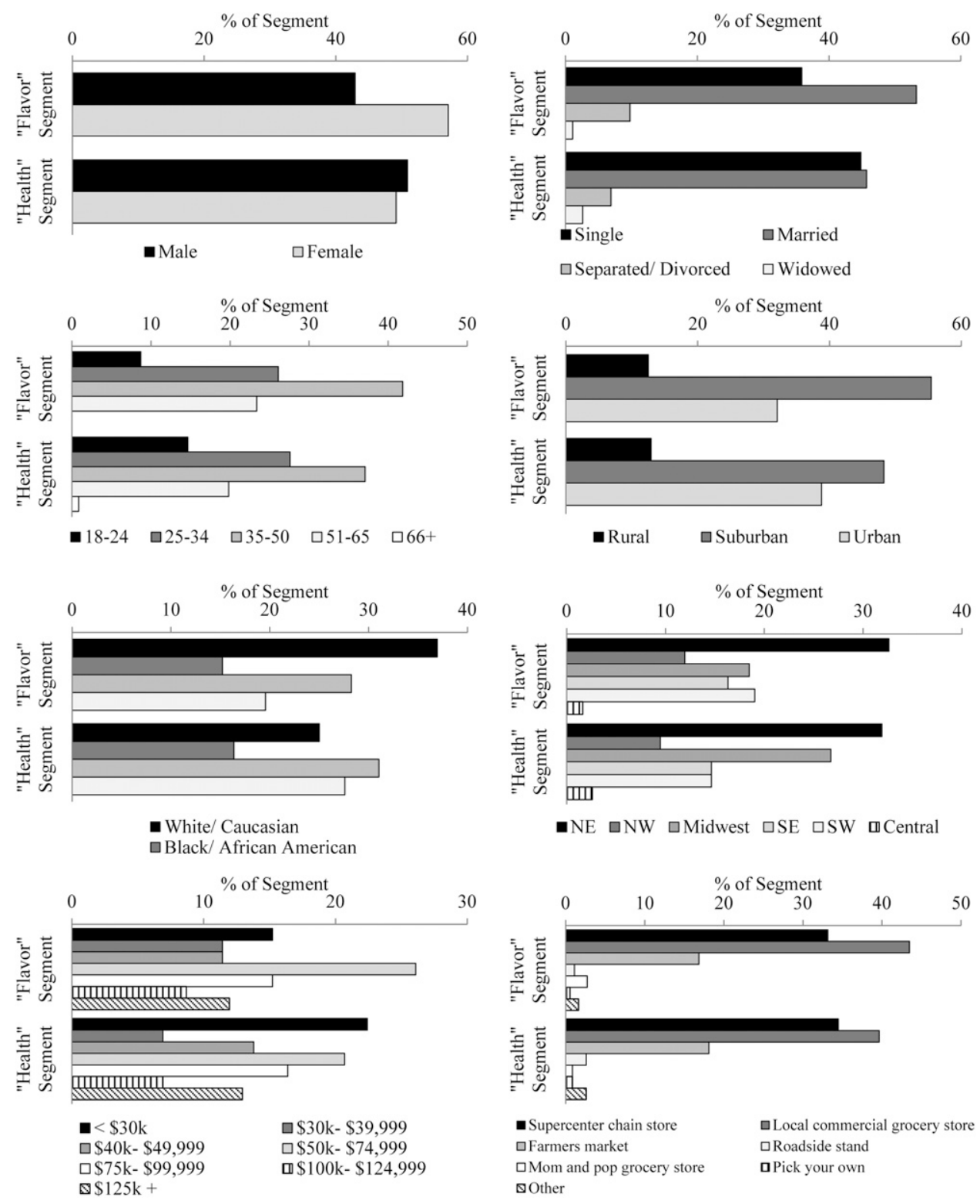

Fig. 3. Reported demographics of the two segments identified through K-cluster analysis of the "Ideal Fresh Blueberry" consumer perception survey (total subjects $=300$ ). Demographics are reported as percentage of the indicated segment. "Flavor" segment $n=184$, "health" segment $n=116$.

supply chain. To target the largest population segment, breeders should focus on improving blueberry flavor as experienced by the consumer. This requires study of genetically regulated blueberry biochemistry available to the breeder as well as the exploration of environmental variables controlled by the producers that could affect flavor biochemistry such as soil nutrients and postharvest storage effects. Most importantly, these studies should incorporate consumer flavor panels that empirically determine flavor biochemistry goals for the breeder. A similar approach should be taken to eliminate genetics or environmental variables that may cause the negative texture qualities rejected by consumers belonging to either segment. Marketing of individual blueberry cultivars for superior flavor could also benefit consumers desiring an enhanced sensory experience from their blueberries and could benefit producers by allowing them to set premium price points. The marketing link of the supply chain would do well to continue highlighting the health benefits associated with eating blueberry fruit.

\section{Literature Cited}

Albrigo, L.G., P.M. Lyrene, and B. Freeman. 1980. Waxes and other surface characteristics of fruit and leaves of native Vaccinium elliotti Chapm. J. Amer. Soc. Hort. Sci. 105:230-235.

Behe, B., R. Nelson, S. Barton, C. Hall, C.D. Safley, and S. Turner. 1999. Consumer preferences for geranium flower color, leaf variegation, and price. HortScience 34:740-742.

Behe, B.K. 2006. Conjoint analysis reveals consumers prefer long, thin asparagus spears. HortScience 41:1259-1262.

Behe, B.K., B.L. Campbell, C.R. Hall, H. Khachatryan, J.H. Dennis, and C. Yue. 2013. Consumer preferences for local and sustainable plant production characteristics. HortScience 48:200-208.

Brazelton, C. 2013. 2012 World blueberry acreage and production report. North American Highbush Blueberry Council, Folsom, CA.
Cassidy, A., K.J. Mukamal, L. Liu, M. Franz, A.H. Eliassen, and E.B. Rimm. 2013. High anthocyanin intake is associated with a reduced risk of myocardial infarction in young and middle-aged women. Circulation 127:188-196.

Clark, J.R. and C.E. Finn. 2010. Register of new fruit and nut cultivars: List 45 . HortScience 45:716-756.

Colquhoun, T.A., L.A. Levin, H.R. Moskowitz, V.M. Whitaker, D.G. Clark, and K.M. Folta. 2012. Framing the perfect strawberry: An exercise in consumer-assisted selection of fruit crops. J. Berry Res. 2:45-61.

DellaVigna, S. 2009. Psychology and economics: Evidence from the field. J. Econ. Lit. 47: 315-372.

Fan, Z.L., Z.Y. Wang, L.L. Zuo, and S.Q. Tian. 2012. Protective effect of anthocyanins from lingonberry on radiation-induced damages. Int. J. Environ. Res. Public Health 9:4732-4743.

Fresh Trends. 2011. The packer. Vance Publishing, Lenexa, KS

Fresh Trends. 2012. The packer. Vance Publishing, Lenexa, KS. 
Fresh Trends. 2013. The packer. Vance Publishing, Lenexa, KS.

Green, P.E. and A.M. Krieger. 1991. Segmenting markets with conjoint analysis. J. Mark. 55: 20-31.

Heim, K.C., P. Angers, S. Leonhart, and B.W. Ritz. 2012. Anti-inflammatory and neuroactive properties of selected fruit extracts. J. Med. Food $15: 851-854$

Jaeger, S.R., R. Harker, C.M. Triggs, A. Gunson, R.L. Campbell, R. Jackman, and C. RequejoJackman. 2011. Determining consumer purchase intentions: The importance of dry matter, size, and price of kiwifruit. J. Food Sci. 76: S177-S184.

Krikorian, R., M.D. Shidler, T.A. Nash, W. Kalt, M.R. Vinqvist-Tymchuk, B. Shukitt-Hale, and J.A. Joseph. 2010. Blueberry supplementation improves memory in older adults. J. Agr. Food Chem. 58:3996-4000.

Levin, L.A., K.M. Langer, D.G. Clark, T.A. Colquhoun, J.L. Callaway, and H.R. Moskowitz. 2012. Using mind genomics (R) to identify essential elements of a flower product. HortScience 47:1658-1665.

Li, C.Y., J. Feng, W.Y. Huang, and X.T. An. 2013. Composition of polyphenols and antioxidant activity of rabbiteye blueberry (Vaccinium ashei) in Nanjing. J. Agr. Food Chem. 61:523-531.

Liu, Y.X., X. Song, D. Zhang, F. Zhou, D. Wang, Y. Wei, F. Gao, L. Xie, G. Jia, W. Wu, and B. Ji. 2012. Blueberry anthocyanins: Protection against ageing and light-induced damage in retinal pigment epithelial cells. Brit. J. Nutr. 108:16-27.
McAnulty, L.S., D.C. Nieman, C.L. Dumke, L.A. Shooter, D.A. Henson, A.C. Utter, G. Milne, and S.R. McAnulty. 2011. Effect of blueberry ingestion on natural killer cell counts, oxidative stress, and inflammation prior to and after $2.5 \mathrm{~h}$ of running. Appl. Physiol. Nutr. Metab. 36:976-984.

Moskowitz, H.R. 2012. 'Mind genomics': The experimental, inductive science of the ordinary, and its application to aspects of food and feeding. Physiol. Behav. 107:606-613.

Moskowitz, H.R. and A. Gofman. 2007. Selling blue elephants. Wharton School Publishing, Upper Saddle River, NJ.

Moskowitz, H.R., A. Gofman, J. Beckley, and H. Ashman. 2006. Founding a new science: Mind genomics. J. Sens. Stud. 21:266-307.

Okie, W.R. 1999. Register of new fruit and nut varieties list 39. HortScience 34:181-205.

Park, C.W. and V.P. Lessig. 1981. Familiarity and its impact on consumer decision biases and heuristics. J. Consum. Res. 8:223-231.

Price, J. and J. Riis. 2012. Behavioral economics and the psychology of fruit and vegetable consumption: A scientific overview, 2012. Produce for Better Health Foundation. 12 Feb. 2014. <http://www.PBHFoundation.org $>$.

Redelmeier, D.A. and V.M. Dickinson. 2011. Determining whether a patient is feeling better: Pitfalls from the science of human perception. J. Gen. Intern. Med. 26:900-906.

Retamales, J.B., R. Godoy, C. Moggia, G.A. Lobos, and S. Romero. 2014. CPPU sprays alter blueberry (Vaccinium corymbosum L. 'Duke') fruit quality at harvest and its behavior in postharvest. Acta Hort. 1017:189-193.
Saftner, R., J. Polashock, M. Ehlenfeldt, and B. Vinyard. 2008. Instrumental and sensory quality characteristics of blueberry fruit from twelve cultivars. Postharvest Biol. Technol. 49:19-26.

Scalzo, J., S. Dierking, W. Dierking, S. Miller, C. Edwards, and P. Alspach. 2009. 'Hortblue Poppins': New cultivar for the home garden. Acta Hort. 810:157-162.

Schwieterman, M.L., T.A. Colquhoun, E.A. Jaworski, L.M. Bartoshuk, J.L. Gilbert, D.M. Tieman, A.Z. Odabasi, H.K. Moskowitz, K.M. Folta, H.J. Klee, C.A. Sims, V.M. Whitaker, and D.G. Clark. 2014. Strawberry flavor: Diversechemical compositions, a seasonal influence, and effects on sensory perception. PLoS One 9:E88446.

Shukitt-Hale, B. 2012. Blueberries and neuronal aging. Gerontology 58:518-523.

Tipton, D.A., J.P. Babu, and M.Kh. Dabbous. 2013. Effects of cranberry components on human aggressive periodontitis gingival fibroblasts. J. Periodontal Res. 48:433-442.

USDA. 2013. Noncitrus fruits and nuts 2012 summary. 25 Jan. 2013. <http://usda.mannlib. cornell.edu/usda/nass/NoncFruiNu//2010s/2013/ NoncFruiNu-01-25-2013.pdf>.

Yousef, G.G., A.F. Brown, Y. Funakoshi, F. Mbeunkui, M.H. Grace, J.R. Ballington, A. Loraine, and M.A. Lila. 2013. Efficient quantification of the health-relevant anthocyanin and phenolic acid profiles in commercial cultivars and breeding selections of blueberries (Vaccinium spp.). J. Agr. Food Chem. 61:4806-4815. 


\begin{tabular}{llcc} 
& \multicolumn{1}{c}{ Gender } & Male & Female \\
\hline & \multicolumn{1}{c}{ Base size } & 138 & 162 \\
& & 37 & 44 \\
\hline A1 & Crispy berry ...pops in your mouth & 6 & 2 \\
A2 & Mushy...melts in your mouth & -10 & -17 \\
A3 & A soft berry & -5 & -4 \\
A4 & Firm with no give, like a grape & 1 & -4 \\
A5 & Thin skin that melts away & 3 & -6 \\
A6 & Tough, chewy skin & -11 & $-22 \ddagger$ \\
B1 & Smooth texture without seeds & 0 & 4 \\
B2 & Lots of seeds, a bit of grit & $-13 \neq$ & -25 \\
B3 & Full of juice & 6 & 9 \\
B4 & Meaty, not juicy & -11 & -7 \\
B5 & Mealy, pasty and dry & $-22 \ddagger$ & $-23 \ddagger$ \\
B6 & Light and airy & 1 & 0 \\
C1 & The biggest berries you've ever seen & 6 & 4 \\
C2 & Petite berries & -1 & 1 \\
C3 & Tiny...to eat bunches at a time & -4 & -2 \\
C4 & As big as a large marble & 2 & 7 \\
C5 & Small, pea-sized & -4 & -4 \\
C6 & Medium, dime-sized & 2 & 5 \\
D1 & Deep blue, almost black color & 8 & 2 \\
D2 & Berries that are a shade of light blue & 3 & -4 \\
D3 & Berries that are bright blue in color & 1 & 4 \\
D4 & Blueberries with a soft, cloudy white coating & 3 & -6 \\
D5 & Berries are dark blue throughout & 8 & 4 \\
D6 & Dark blue outside, pale inside & 6 & 1 \\
E1 & Fruity flavor & 8 & 4 \\
E2 & Bold and intense blueberry flavor & $13 *$ & $10^{*}$ \\
E3 & Complex flavor with a hint of bitter & -3 & -8 \\
E4 & So sweet, no sugar needed & $14^{*}$ & $11^{*}$ \\
E5 & Tart berry that wakes the taste buds & 3 & -7 \\
E6 & Mild flavor, but compliments well & -2 & -4 \\
F1 & Full of antioxidants & 7 & 7 \\
F2 & No fat, no cholesterol & -3 & 2 \\
F3 & High in vitamin C & 3 & 1 \\
F4 & A rich source of dietary fiber & 0 & 4 \\
F5 & Organic berries & 7 & 4 \\
F6 & A low-carbohydrate source of nutrients & -2 \\
\hline
\end{tabular}

${ }^{z}$ The total sample data was separated by gender. The base sizes, constants, and interest ratings per element for each subject population are listed in the table. The two elements with the highest interest ranking in each group are denoted by $*$ and the bottom two ranked elements are donated by $\ddagger$. 


\begin{tabular}{|c|c|c|c|c|c|}
\hline & Age (years) & $18-24$ & $25-34$ & $35-50$ & $51-65$ \\
\hline & Base size & 33 & 80 & 120 & 66 \\
\hline & Constant & 56 & 42 & 28 & 50 \\
\hline A1 & Crispy berry...pops in your mouth & -7 & 3 & 11 & -2 \\
\hline A2 & Mushy...melts in your mouth & $-24 \ddagger$ & -9 & -12 & -18 \\
\hline A3 & A soft berry & -12 & -8 & 3 & -9 \\
\hline A4 & Firm with no give, like a grape & -10 & -3 & 4 & -6 \\
\hline A5 & Thin skin that melts away & -19 & -1 & 4 & -4 \\
\hline A6 & Tough, chewy skin & -8 & $-19 \neq$ & -10 & $-31 \neq$ \\
\hline $\mathrm{B} 1$ & Smooth texture without seeds & -9 & 7 & 3 & 2 \\
\hline B2 & Lots of seeds, a bit of grit & $-26 \ddagger$ & -15 & $-18 \neq$ & -25 \\
\hline B3 & Full of juice & 4 & 8 & 8 & 7 \\
\hline B4 & Meaty, not juicy & -14 & -6 & -9 & -8 \\
\hline B5 & Mealy, pasty and dry & -22 & $-20 \neq$ & $-22 \ddagger$ & $-27 \ddagger$ \\
\hline B6 & Light and airy & 2 & -2 & 1 & 2 \\
\hline $\mathrm{C} 1$ & The biggest berries you've ever seen & -7 & 5 & 10 & 2 \\
\hline $\mathrm{C} 2$ & Petite berries & -2 & 4 & 3 & -8 \\
\hline $\mathrm{C} 3$ & Tiny...to eat bunches at a time & -8 & -2 & 4 & -13 \\
\hline $\mathrm{C} 4$ & As big as a large marble & 2 & 5 & 10 & -4 \\
\hline $\mathrm{C} 5$ & Small, pea-sized & -11 & -2 & 1 & -11 \\
\hline C6 & Medium, dime-sized & -5 & $10 *$ & 8 & -6 \\
\hline D1 & Deep blue, almost black color & -1 & 9 & 7 & 0 \\
\hline $\mathrm{D} 2$ & Berries that are a shade of light blue & -2 & -1 & 0 & -2 \\
\hline D3 & Berries that are bright blue in color & -1 & 6 & 4 & 1 \\
\hline D4 & Blueberries with a soft, cloudy white coating & -1 & -2 & 1 & -8 \\
\hline D5 & Berries are dark blue throughout & 3 & 7 & 10 & 1 \\
\hline D6 & Dark blue outside, pale inside & -8 & 6 & 5 & 4 \\
\hline E1 & Fruity flavor & -3 & 6 & 9 & 6 \\
\hline E2 & Bold and intense blueberry flavor & $7 *$ & 7 & $16^{*}$ & $11^{*}$ \\
\hline E3 & Complex flavor with a hint of bitter & -1 & -7 & -6 & -4 \\
\hline E4 & So sweet, no sugar needed & $6^{*}$ & 8 & $16^{*}$ & $17 *$ \\
\hline E5 & Tart berry that wakes the taste buds & -9 & -4 & 2 & -4 \\
\hline E6 & Mild flavor, but compliments well & -13 & 3 & -1 & -7 \\
\hline F1 & Full of antioxidants & 5 & 6 & 10 & 2 \\
\hline $\mathrm{F} 2$ & No fat, no cholesterol & -6 & 3 & 4 & -7 \\
\hline F3 & High in vitamin $\mathrm{C}$ & -3 & -3 & 6 & 5 \\
\hline F4 & A rich source of dietary fiber & 3 & 0 & 7 & -3 \\
\hline F5 & Organic berries & 0 & $10 *$ & 10 & -7 \\
\hline F6 & A low-carbohydrate source of nutrients & -2 & -6 & 3 & -2 \\
\hline
\end{tabular}

${ }^{\mathrm{z}}$ The total sample data was separated by age. The base sizes, constants, and interest ratings per element for each subject population are listed in the table. The two elements with the highest interest ranking in each group are denoted by * and the bottom two ranked elements are donated by $\ddagger$. 


\begin{tabular}{|c|c|c|c|c|c|}
\hline & Ethnicity & $\begin{array}{c}\text { White/Caucasia } \\
n\end{array}$ & $\begin{array}{l}\text { Black/Africa } \\
\text { n American }\end{array}$ & $\begin{array}{l}\text { Hispanic } \\
\text { / Latino }\end{array}$ & Asian \\
\hline & Base size & 97 & 47 & 88 & 68 \\
\hline & Constant & 36 & 49 & 34 & 51 \\
\hline A1 & Crispy berry...pops in your mouth & 3 & 4 & 7 & 2 \\
\hline A2 & Mushy...melts in your mouth & $-21 \neq$ & -18 & -6 & -10 \\
\hline A3 & A soft berry & -4 & -8 & 0 & -9 \\
\hline A4 & Firm with no give, like a grape & -1 & -7 & -5 & 4 \\
\hline A5 & Thin skin that melts away & -7 & 2 & 0 & -2 \\
\hline A6 & Tough, chewy skin & $-21 \neq$ & -20 & -18 & -8 \\
\hline B1 & Smooth texture without seeds & 4 & -4 & 5 & 1 \\
\hline B2 & Lots of seeds, a bit of grit & -20 & -20 & $-21 \neq$ & $-16 \neq$ \\
\hline B3 & Full of juice & 12 & -4 & 8 & $7 *$ \\
\hline B4 & Meaty, not juicy & -3 & $-25 \ddagger$ & -6 & -10 \\
\hline B5 & Mealy, pasty and dry & -21 & $-34 \ddagger$ & $-23 \ddagger$ & $-18 \neq$ \\
\hline B6 & Light and airy & -4 & -5 & 7 & 2 \\
\hline $\mathrm{C} 1$ & The biggest berries you've ever seen & 4 & 3 & 7 & 4 \\
\hline $\mathrm{C} 2$ & Petite berries & -5 & 5 & 4 & 0 \\
\hline $\mathrm{C} 3$ & Tiny...to eat bunches at a time & -9 & 0 & 4 & -5 \\
\hline $\mathrm{C} 4$ & As big as a large marble & 3 & 7 & 7 & 2 \\
\hline $\mathrm{C} 5$ & Small, pea-sized & -7 & -2 & -1 & -6 \\
\hline C6 & Medium, dime-sized & 2 & 5 & 7 & 2 \\
\hline D1 & Deep blue, almost black color & 5 & 5 & 5 & 5 \\
\hline D2 & Berries that are a shade of light blue & -2 & -1 & 2 & -4 \\
\hline D3 & Berries that are bright blue in color & 7 & -4 & 6 & -3 \\
\hline D4 & Blueberries with a soft, cloudy white coating & -2 & -3 & 0 & -4 \\
\hline D5 & Berries are dark blue throughout & 8 & 7 & 4 & 4 \\
\hline D6 & Dark blue outside, pale inside & 11 & 0 & 2 & -4 \\
\hline E1 & Fruity flavor & 7 & 5 & $13^{*}$ & -4 \\
\hline E2 & Bold and intense blueberry flavor & $13^{*}$ & $12 *$ & 7 & $13^{*}$ \\
\hline E3 & Complex flavor with a hint of bitter & -3 & -3 & -8 & -9 \\
\hline E4 & So sweet, no sugar needed & $17 *$ & $16^{*}$ & $12 *$ & 5 \\
\hline E5 & Tart berry that wakes the taste buds & 2 & 0 & -6 & -6 \\
\hline E6 & Mild flavor, but compliments well & -2 & 2 & -6 & -5 \\
\hline F1 & Full of antioxidants & 5 & 11 & 11 & 2 \\
\hline $\mathrm{F} 2$ & No fat, no cholesterol & 3 & -4 & 3 & -5 \\
\hline F3 & High in vitamin $\mathrm{C}$ & -1 & 11 & 7 & -6 \\
\hline F4 & A rich source of dietary fiber & 5 & 1 & 6 & -7 \\
\hline F5 & Organic berries & 0 & 8 & 10 & 4 \\
\hline F6 & A low-carbohydrate source of nutrients & 2 & -1 & -2 & -4 \\
\hline
\end{tabular}

${ }^{2}$ The total sample data was separated by ethnicity. The base sizes, constants, and interest ratings per element for each subject population are listed in the table. The two elements with the highest interest ranking in each group are denoted by $*$, and the bottom two ranked elements are donated by $\ddagger$. 


\begin{tabular}{|c|c|c|c|c|c|c|c|c|}
\hline & Income & $\begin{array}{c}\text { Under } \\
\$ 30,00 \\
0\end{array}$ & $\begin{array}{c}\$ 30,00 \\
0- \\
\$ 39,99 \\
9\end{array}$ & $\begin{array}{c}\$ 40,00 \\
0- \\
\$ 49,99 \\
9\end{array}$ & $\begin{array}{c}\$ 50,00 \\
0- \\
\$ 74,99 \\
9\end{array}$ & $\begin{array}{c}\$ 75,00 \\
0- \\
\$ 99,99 \\
9\end{array}$ & $\begin{array}{c}\$ 100,00 \\
0- \\
\$ 124,99 \\
9\end{array}$ & $\begin{array}{c}\$ 125,000 \\
+\end{array}$ \\
\hline & Base size & 54 & 29 & 37 & 72 & 47 & 24 & 37 \\
\hline & Constant & 54 & 32 & 56 & 27 & 47 & 56 & 22 \\
\hline A1 & Crispy berry...pops in your mouth & -2 & -1 & $11^{*}$ & 7 & -3 & 10 & 9 \\
\hline $\mathrm{A} 2$ & Mushy...melts in your mouth & -11 & -14 & -20 & -4 & $-25 \neq$ & -23 & $-7 \neq$ \\
\hline A3 & A soft berry & -11 & -4 & -10 & 7 & -15 & -4 & 0 \\
\hline A4 & Firm with no give, like a grape & -9 & 7 & -1 & 3 & -7 & 1 & -4 \\
\hline A5 & Thin skin that melts away & -3 & -5 & -6 & 6 & -11 & -10 & 5 \\
\hline A6 & Tough, chewy skin & -15 & -9 & $-21 \neq$ & -14 & $-30 \neq$ & -21 & $-8 \neq$ \\
\hline B1 & Smooth texture without seeds & -6 & 5 & 5 & 9 & -5 & -3 & 8 \\
\hline B2 & Lots of seeds, a bit of grit & $-23 \neq$ & $-20 \neq$ & $-28 \neq$ & $-15 \neq$ & -14 & $-34 \neq$ & -12 \\
\hline B3 & Full of juice & $7 *$ & 1 & 3 & 5 & 7 & $13^{*}$ & $19^{*}$ \\
\hline B4 & Meaty, not juicy & -13 & -1 & -18 & -2 & -17 & -14 & 1 \\
\hline B5 & Mealy, pasty and dry & $-29 \neq$ & $-28 \neq$ & -19 & $-18 \neq$ & -23 & $-37 \neq$ & -12 \\
\hline B6 & Light and airy & -2 & -6 & 0 & 2 & -2 & -3 & 11 \\
\hline $\mathrm{C} 1$ & The biggest berries you've ever seen & -4 & -1 & 9 & 11 & $10 *$ & -1 & 3 \\
\hline $\mathrm{C} 2$ & Petite berries & -3 & 8 & -8 & 2 & 3 & -12 & 7 \\
\hline $\mathrm{C} 3$ & Tiny...to eat bunches at a time & -12 & 5 & -8 & 8 & -8 & -10 & -2 \\
\hline $\mathrm{C} 4$ & As big as a large marble & 3 & 13 & 5 & 5 & 5 & -10 & 8 \\
\hline C5 & Small, pea-sized & -10 & -7 & -4 & 1 & -1 & -16 & 1 \\
\hline C6 & Medium, dime-sized & -5 & 9 & -1 & 7 & 7 & -4 & 10 \\
\hline D1 & Deep blue, almost black color & 1 & 2 & 10 & 7 & 4 & -2 & 9 \\
\hline $\mathrm{D} 2$ & Berries that are a shade of light blue & 5 & -7 & -2 & 5 & -10 & -7 & 0 \\
\hline D3 & Berries that are bright blue in color & 0 & 11 & -5 & 7 & -2 & -3 & 10 \\
\hline D4 & Blueberries with a soft, cloudy white coating & -2 & -2 & -9 & 4 & -8 & -1 & 0 \\
\hline D5 & Berries are dark blue throughout & 3 & 4 & 6 & 6 & 9 & -2 & 13 \\
\hline D6 & Dark blue outside, pale inside & 2 & -8 & -6 & 9 & 5 & 2 & 12 \\
\hline E1 & Fruity flavor & 3 & 6 & 5 & 11 & 4 & -8 & 12 \\
\hline E2 & Bold and intense blueberry flavor & 6 & 6 & $13^{*}$ & $16^{*}$ & 5 & 10 & $21^{*}$ \\
\hline E3 & Complex flavor with a hint of bitter & -13 & -7 & -14 & -6 & -10 & -3 & 15 \\
\hline E4 & So sweet, no sugar needed & $9 *$ & $20^{*}$ & 6 & $17 *$ & $10^{*}$ & 5 & 17 \\
\hline E5 & Tart berry that wakes the taste buds & -10 & -1 & 3 & 2 & -7 & -5 & 0 \\
\hline E6 & Mild flavor, but compliments well & -6 & 0 & -7 & 1 & -6 & -9 & 0 \\
\hline F1 & Full of antioxidants & 4 & $16^{*}$ & 5 & 7 & 8 & 0 & 10 \\
\hline $\mathrm{F} 2$ & No fat, no cholesterol & -3 & -4 & 5 & 2 & 4 & -3 & -4 \\
\hline $\mathrm{F} 3$ & High in vitamin $\mathrm{C}$ & 6 & -1 & -6 & 10 & -4 & -1 & 2 \\
\hline $\mathrm{F} 4$ & A rich source of dietary fiber & 2 & 4 & 6 & -3 & 9 & -3 & 2 \\
\hline F5 & Organic berries & 6 & 5 & 6 & 11 & 1 & $12 *$ & -9 \\
\hline F6 & A low-carbohydrate source of nutrients & 0 & -13 & 2 & -3 & -2 & -1 & 9 \\
\hline
\end{tabular}

${ }^{\mathrm{z}}$ The total sample data was separated by income. The base sizes, constants, and interest ratings per element for each subject population are listed in the table. The two elements with the highest interest ranking in each group are denoted by $*$ and the bottom two ranked elements are donated by $\ddagger$. 


\begin{tabular}{|c|c|c|c|c|}
\hline & Relationship status & Single & Married & Separated/divorced \\
\hline & Base size & 118 & 151 & 26 \\
\hline & Constant & 37 & 42 & 49 \\
\hline A1 & Crispy berry...pops in your mouth & 5 & 3 & 5 \\
\hline A2 & Mushy...melts in your mouth & -13 & -15 & -11 \\
\hline A3 & A soft berry & -7 & -1 & -8 \\
\hline A4 & Firm with no give, like a grape & -3 & -2 & -2 \\
\hline A5 & Thin skin that melts away & -2 & -2 & -2 \\
\hline A6 & Tough, chewy skin & -14 & $-19 \neq$ & -11 \\
\hline B1 & Smooth texture without seeds & 0 & 4 & 2 \\
\hline B2 & Lots of seeds, a bit of grit & $-22 \neq$ & -16 & $-27 \neq$ \\
\hline B3 & Full of juice & 8 & 8 & 3 \\
\hline B4 & Meaty, not juicy & -14 & -5 & -7 \\
\hline B5 & Mealy, pasty and dry & $-23 \neq$ & $-23 \neq$ & -17 \\
\hline B6 & Light and airy & -1 & 2 & 0 \\
\hline $\mathrm{C} 1$ & The biggest berries you've ever seen & 7 & 3 & 4 \\
\hline $\mathrm{C} 2$ & Petite berries & 4 & 1 & $-21 \neq$ \\
\hline $\mathrm{C} 3$ & Tiny...to eat bunches at a time & -1 & -2 & -19 \\
\hline $\mathrm{C} 4$ & As big as a large marble & 8 & 4 & -2 \\
\hline $\mathrm{C} 5$ & Small, pea-sized & 0 & -5 & -17 \\
\hline C6 & Medium, dime-sized & 5 & 5 & -7 \\
\hline D1 & Deep blue, almost black color & 8 & 3 & -2 \\
\hline D2 & Berries that are a shade of light blue & -1 & -3 & $10 *$ \\
\hline D3 & Berries that are bright blue in color & 3 & 4 & -3 \\
\hline D4 & Blueberries with a soft, cloudy white coating & 1 & -4 & -3 \\
\hline D5 & Berries are dark blue throughout & 6 & 5 & 7 \\
\hline D6 & Dark blue outside, pale inside & -1 & 6 & 7 \\
\hline E1 & Fruity flavor & 11 & 2 & 6 \\
\hline E2 & Bold and intense blueberry flavor & $12 *$ & $12 *$ & 7 \\
\hline E3 & Complex flavor with a hint of bitter & -4 & -5 & -15 \\
\hline E4 & So sweet, no sugar needed & $12 *$ & $12 *$ & $15^{*}$ \\
\hline E5 & Tart berry that wakes the taste buds & 0 & -5 & 1 \\
\hline E6 & Mild flavor, but compliments well & -5 & -2 & 1 \\
\hline $\mathrm{F} 1$ & Full of antioxidants & 6 & 6 & 6 \\
\hline $\mathrm{F} 2$ & No fat, no cholesterol & -1 & -1 & 4 \\
\hline F3 & High in vitamin $\mathrm{C}$ & 6 & 0 & -6 \\
\hline F4 & A rich source of dietary fiber & 5 & 1 & -6 \\
\hline F5 & Organic berries & 6 & 6 & -7 \\
\hline F6 & A low-carbohydrate source of nutrients & 0 & -3 & -1 \\
\hline
\end{tabular}

${ }^{{ }^{2} \text { The total sample data was separated by relationship status. The base sizes, constants, and interest ratings per element for each subject population are listed in the }}$ table. The two elements with the highest interest ranking in each group are denoted by * and the bottom two ranked elements are donated by $\ddagger$. 


\begin{tabular}{|c|c|c|c|c|}
\hline & Neighborhood & Rural & Suburban & Urban \\
\hline & Base size & 38 & 158 & 104 \\
\hline & Constant & 37 & 45 & 36 \\
\hline A1 & Crispy berry...pops in your mouth & 4 & 3 & 6 \\
\hline $\mathrm{A} 2$ & Mushy...melts in your mouth & -16 & -14 & -12 \\
\hline A3 & A soft berry & 4 & -6 & -6 \\
\hline A4 & Firm with no give, like a grape & -9 & 1 & -3 \\
\hline A5 & Thin skin that melts away & -1 & -4 & 0 \\
\hline A6 & Tough, chewy skin & -13 & -17 & -17 \\
\hline B1 & Smooth texture without seeds & 10 & -2 & 6 \\
\hline B2 & Lots of seeds, a bit of grit & $-18 \neq$ & $-20 \neq$ & $-20 \neq$ \\
\hline B3 & Full of juice & 4 & 6 & 11 \\
\hline B4 & Meaty, not juicy & -5 & -11 & -6 \\
\hline B5 & Mealy, pasty and dry & $-20 \neq$ & $-24 \neq$ & $-21 \neq$ \\
\hline B6 & Light and airy & 1 & -1 & 3 \\
\hline $\mathrm{C} 1$ & The biggest berries you've ever seen & 3 & 4 & 7 \\
\hline $\mathrm{C} 2$ & Petite berries & -5 & 0 & 2 \\
\hline $\mathrm{C} 3$ & Tiny...to eat bunches at a time & -4 & -5 & 1 \\
\hline $\mathrm{C} 4$ & As big as a large marble & 2 & 4 & 6 \\
\hline C5 & Small, pea-sized & -11 & -4 & -1 \\
\hline C6 & Medium, dime-sized & -1 & 4 & 5 \\
\hline D1 & Deep blue, almost black color & 2 & 3 & 8 \\
\hline D2 & Berries that are a shade of light blue & 5 & -4 & 2 \\
\hline D3 & Berries that are bright blue in color & 4 & 0 & 7 \\
\hline D4 & Blueberries with a soft, cloudy white coating & 5 & -6 & 1 \\
\hline D5 & Berries are dark blue throughout & 4 & 5 & 8 \\
\hline D6 & Dark blue outside, pale inside & $12 *$ & 2 & 3 \\
\hline E1 & Fruity flavor & $10 *$ & 1 & 12 \\
\hline $\mathrm{E} 2$ & Bold and intense blueberry flavor & 5 & $7 *$ & $20 *$ \\
\hline E3 & Complex flavor with a hint of bitter & -12 & -7 & -3 \\
\hline E4 & So sweet, no sugar needed & 4 & $12 *$ & $16^{*}$ \\
\hline E5 & Tart berry that wakes the taste buds & -1 & -5 & 1 \\
\hline E6 & Mild flavor, but compliments well & -4 & -8 & 4 \\
\hline $\mathrm{F} 1$ & Full of antioxidants & 4 & 7 & 8 \\
\hline $\mathrm{F} 2$ & No fat, no cholesterol & 0 & -3 & 5 \\
\hline F3 & High in vitamin $\mathrm{C}$ & 8 & 0 & 3 \\
\hline F4 & A rich source of dietary fiber & 2 & 2 & 3 \\
\hline F5 & Organic berries & 8 & -1 & 12 \\
\hline F6 & A low-carbohydrate source of nutrients & -2 & 0 & -2 \\
\hline
\end{tabular}

${ }^{\mathrm{z}}$ The total sample data was separated by neighborhood classification. The base sizes, constants, and interest ratings per element for each subject population are listed in the table. The two elements with the highest interest ranking in each group are denoted by $*$ and the bottom two ranked elements are donated by $\ddagger$. 


\begin{tabular}{|c|c|c|c|c|c|c|}
\hline & U.S. region & Northeast & Northwest & Midwest & Southeast & Southwest \\
\hline & Base size & 97 & 33 & 65 & 47 & 52 \\
\hline & Constant & 39 & 24 & 27 & 56 & 53 \\
\hline A1 & Crispy berry...pops in your mouth & 7 & 2 & 3 & -1 & 4 \\
\hline A2 & Mushy...melts in your mouth & -19 & -6 & -9 & -16 & -11 \\
\hline A3 & A soft berry & -4 & -4 & -2 & -9 & -6 \\
\hline A4 & Firm with no give, like a grape & -1 & -3 & -1 & -3 & -4 \\
\hline A5 & Thin skin that melts away & 1 & -4 & -3 & 1 & -8 \\
\hline A6 & Tough, chewy skin & -13 & $-22 \ddagger$ & -18 & $-20 \neq$ & -15 \\
\hline B1 & Smooth texture without seeds & 6 & -1 & 7 & -3 & -5 \\
\hline B2 & Lots of seeds, a bit of grit & $-21 \neq$ & -12 & $-19 \neq$ & -19 & $-20 \ddagger$ \\
\hline B3 & Full of juice & 6 & 19 & 10 & -1 & $7 *$ \\
\hline B4 & Meaty, not juicy & -4 & -5 & -13 & -7 & -14 \\
\hline B5 & Mealy, pasty and dry & $-23 \neq$ & $-24 \ddagger$ & $-24 \ddagger$ & $-22 \neq$ & $-17 \neq$ \\
\hline B6 & Light and airy & -2 & 7 & 4 & -5 & 4 \\
\hline $\mathrm{C} 1$ & The biggest berries you've ever seen & 6 & 9 & 10 & 0 & 1 \\
\hline $\mathrm{C} 2$ & Petite berries & 2 & 10 & -1 & -4 & -4 \\
\hline $\mathrm{C} 3$ & Tiny...to eat bunches at a time & 2 & 2 & -8 & -5 & -5 \\
\hline $\mathrm{C} 4$ & As big as a large marble & 10 & 6 & 4 & 5 & -4 \\
\hline $\mathrm{C} 5$ & Small, pea-sized & -8 & 4 & 1 & -6 & -5 \\
\hline C6 & Medium, dime-sized & 4 & 14 & 4 & 4 & -1 \\
\hline D1 & Deep blue, almost black color & 6 & 5 & 9 & -1 & 3 \\
\hline D2 & Berries that are a shade of light blue & 3 & -3 & 0 & -13 & 4 \\
\hline D3 & Berries that are bright blue in color & 8 & 5 & 11 & -10 & -5 \\
\hline D4 & $\begin{array}{l}\text { Blueberries with a soft, cloudy white } \\
\text { coating }\end{array}$ & -1 & 8 & -2 & -13 & 1 \\
\hline D5 & Berries are dark blue throughout & 6 & 4 & 10 & 4 & 3 \\
\hline D6 & Dark blue outside, pale inside & 6 & 5 & 10 & -4 & -5 \\
\hline E1 & Fruity flavor & 9 & 12 & 6 & 0 & 2 \\
\hline E2 & Bold and intense blueberry flavor & $15^{*}$ & $23 *$ & 13 & 3 & 1 \\
\hline E3 & Complex flavor with a hint of bitter & -1 & -5 & -7 & -7 & -11 \\
\hline E4 & So sweet, no sugar needed & $13^{*}$ & $19 *$ & $19 *$ & $11 *$ & 2 \\
\hline E5 & Tart berry that wakes the taste buds & -2 & 6 & 7 & -11 & -12 \\
\hline E6 & Mild flavor, but compliments well & -3 & -3 & -3 & 1 & -9 \\
\hline F1 & Full of antioxidants & 12 & -11 & 13 & -1 & $7 *$ \\
\hline $\mathrm{F} 2$ & No fat, no cholesterol & 0 & 1 & 3 & -5 & 1 \\
\hline F3 & High in vitamin $\mathrm{C}$ & 6 & -11 & 10 & -2 & -4 \\
\hline $\mathrm{F} 4$ & A rich source of dietary fiber & 10 & -5 & 7 & -10 & -1 \\
\hline F5 & Organic berries & 9 & 5 & $17 *$ & -6 & -6 \\
\hline F6 & A low-carbohydrate source of nutrients & 1 & -2 & 0 & -2 & -6 \\
\hline
\end{tabular}

${ }^{2}$ The total sample data was separated by subject?s U.S. region of residence. The base sizes, constants, and interest ratings per element for each subject population are listed in the table. The two elements with the highest interest ranking in each group are denoted by $*$ and the bottom two ranked elements are donated by $\ddagger$. 


\begin{tabular}{|c|c|c|c|c|}
\hline & Blueberry purchase location & \multicolumn{2}{|r|}{$\begin{array}{l}\text { Local } \\
\text { commercial } \\
\text { grocery } \\
\text { store }\end{array}$} & \multirow{2}{*}{$\begin{array}{r}\begin{array}{r}\text { Farmers' } \\
\text { market }\end{array} \\
52\end{array}$} \\
\hline & Base size & 101 & 126 & \\
\hline & Constant & 38 & 34 & 61 \\
\hline A1 & Crispy berry...pops in your mouth & 6 & 4 & 1 \\
\hline A2 & Mushy...melts in your mouth & -12 & -15 & -11 \\
\hline A3 & A soft berry & -5 & -3 & -8 \\
\hline A4 & Firm with no give, like a grape & -2 & -1 & -4 \\
\hline A5 & Thin skin that melts away & 2 & -2 & -11 \\
\hline A6 & Tough, chewy skin & -13 & -20 & -14 \\
\hline B1 & Smooth texture without seeds & 2 & 4 & 4 \\
\hline B2 & Lots of seeds, a bit of grit & $-18 \neq$ & $-21 \neq$ & -26 \\
\hline B3 & Full of juice & 10 & 10 & -1 \\
\hline B4 & Meaty, not juicy & -8 & -5 & $-21 \neq$ \\
\hline B5 & Mealy, pasty and dry & $-20 \neq$ & $-23 \neq$ & $-29 \neq$ \\
\hline B6 & Light and airy & -1 & 1 & 3 \\
\hline $\mathrm{C} 1$ & The biggest berries you've ever seen & 6 & 8 & -4 \\
\hline $\mathrm{C} 2$ & Petite berries & 3 & -3 & -1 \\
\hline $\mathrm{C} 3$ & Tiny...to eat bunches at a time & -2 & -2 & -8 \\
\hline $\mathrm{C} 4$ & As big as a large marble & $11^{*}$ & 5 & -7 \\
\hline $\mathrm{C} 5$ & Small, pea-sized & -1 & -6 & -6 \\
\hline C6 & Medium, dime-sized & 7 & 2 & 2 \\
\hline D1 & Deep blue, almost black color & 7 & 5 & -2 \\
\hline $\mathrm{D} 2$ & Berries that are a shade of light blue & 1 & -4 & -2 \\
\hline D3 & Berries that are bright blue in color & 1 & 7 & -3 \\
\hline D4 & Blueberries with a soft, cloudy white coating & -4 & 1 & -6 \\
\hline D5 & Berries are dark blue throughout & 6 & 8 & 2 \\
\hline D6 & Dark blue outside, pale inside & 3 & 5 & 3 \\
\hline E1 & Fruity flavor & 6 & 8 & 3 \\
\hline E2 & Bold and intense blueberry flavor & 11 & $16^{*}$ & 4 \\
\hline E3 & Complex flavor with a hint of bitter & -6 & 1 & -13 \\
\hline E4 & So sweet, no sugar needed & $11^{*}$ & $19 *$ & 1 \\
\hline E5 & Tart berry that wakes the taste buds & 1 & -5 & 1 \\
\hline E6 & Mild flavor, but compliments well & -7 & 1 & -2 \\
\hline F1 & Full of antioxidants & 6 & 11 & 1 \\
\hline $\mathrm{F} 2$ & No fat, no cholesterol & -3 & 4 & -7 \\
\hline F3 & High in vitamin $\mathrm{C}$ & 5 & 3 & -5 \\
\hline F4 & A rich source of dietary fiber & 6 & 3 & -5 \\
\hline F5 & Organic berries & 4 & 8 & -3 \\
\hline F6 & A low-carbohydrate source of nutrients & 3 & 1 & -10 \\
\hline
\end{tabular}

${ }^{\mathrm{z}}$ The total sample data was separated by blueberry purchase location. The base sizes, constants, and interest ratings per element for each subject population are listed in the table. The two elements with the highest interest ranking in each group are denoted by * and the bottom two ranked elements are donated by $\ddagger$ 